\title{
Evaluation of body dysmorphic disorder in hair loss patients and benefit after hair restoration
}

\author{
Rajendarsingh Rajput, MCh Mumbai, India drrajeshrajput@gmail.com
}

Body Dysmorphic Disorder (BDD) can be defined as excessive concern about an imaginary or marginal defect in physical appearance leading to thoughts or actions creating distress, with social and /or functional impairment of routine life. ${ }^{1-3}$ The patients do not believe that they will benefit from psychiatric help; rather, they believe cosmetic surgery is required for permanent correction of their problem. ${ }^{4}$ The patient with BDD - and almost certainly some patients without BDD but whose expectations have been poorly set up by their surgeons - will still find a residual deformity after the surgery and continue to be dissatisfied. ${ }^{3}$

Studies have reported a prevalence of BDD in $0.7-3 \%$ of the general population, $2.5-5.3 \%$ in college students, and 6-15\% in those consulting for cosmetic surgery. ${ }^{5-9}$ The present-day, lifelong exposure to the media with its display of well groomed bodies often can distort one's perceived body image and can promote a feeling of mismatched body proportions. Most common areas of concern in BDD are skin, hair, and nose. ${ }^{10-12}$

We often find patients who will refuse to remove their cap or who use hair pieces at a young age, even though they have a good amount of hair on their head. We see patients refusing social events and photographs with friends or insisting on photos only at a certain angle where their hair looks good. Many women refuse to have a change in hair style even with only slight thinning on the frontal or temporal area. (Some, but, of course, not all, of these patients may have BDD.) Thus, hair transplant surgeons need to be more aware of BDD.

\section{Patients and Methods}

All 119 patients aged 18 years and older who consulted for hair transplant from January 1, 2010 to July 31, 2010, were counseled and asked to participate in our BDD study. After reading the study questions, 19 patients who felt uncomfortable answering the questions chose not to participate. In fact, we speculate, that these patients are most likely the ones who were most concerned about their appearance and withdrew even at the mention of the condition. Thus, the final study included 100 patients who were reassessed 8 months after their hair transplant.

There are standard questionnaires available for the evaluation of BDD in psychiatry and cosmetic surgery. We modified four different questionnaires to suite our hair loss study.

\section{Patient Evaluation}

Patients made a personal evaluation of the extent of their deformity (Table 1). All the patients scored their deformity as severe to extreme based on the fact that they were concerned about it and had come to request a correction of the real or the perceived defect. The surgeon's assessment of most deformities was mild to moderate indicating that, although the defects looked mild, they were considered as more serious by the patient. The majority of the patients (94\%) agreed to have corrections based on the doctor's guidelines, which were explained as ones following good transplant practices. A very small number (6\%) of patients were adamant about a particular shape or area being

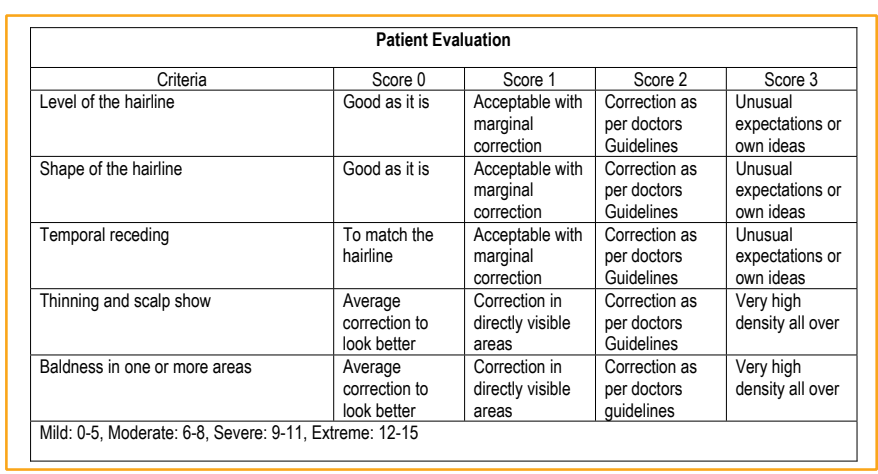

Table 1. Patient Evaluation

transplanted more preferentially, and their requests were accommodated if they fell within the limits of the procedure.

\section{Modified Yale-Brown Obsessive Compulsive Scale}

We did not use the scale for compulsive actions since the obsessive evaluation delivered good insight into the severity of the problem. A similar 5-point rating can be used to evaluate compulsive actions as well. The Yale-Brown Scale is a global standard used in the evaluation, follow-up, and improvement in severity of the dysmorphic thoughts and behavior. It is more often used for cosmetic surgery patients..$^{14,15}$

Patients in our study were asked to rate their obsessive feelings using similar questions that were more specific to hair loss, such as looking into the mirror, spending more time to get the hair set perfectly, wanting to adjust the slightest disturbance in their hair, wearing a cap all the time, refusing to dance or engage in games, etc., where their hair styling might be disturbed, and avoiding photographs and social events. Unlike the specific questions on the Yale-Brown Scale, our questions were not previously vetted to see if they accurately identify patients with BDD. (See Table 2.)

\begin{tabular}{|l|l|l|l|l|l||}
\hline \multicolumn{7}{|c|}{ Yale-Brown Obsessive Scale Modified } \\
\hline \multicolumn{1}{|c|}{ Obsession } & Score 0 & Score 1 & \multicolumn{1}{|c|}{ Score 2 } & \multicolumn{1}{|c|}{ Score 3 } & Score 4 \\
\hline Time spent on obsession & 0 hours & $0-1$ hours & $1-3$ hours & $3-8$ hours & > 8 hours \\
\hline Interference from obsession & None & Mild & $\begin{array}{l}\text { Definite } \\
\text { manageable }\end{array}$ & $\begin{array}{l}\text { Substantial } \\
\text { impairment }\end{array}$ & Incapacitating \\
\hline Distress from obsession & None & Mild & $\begin{array}{l}\text { Moderate } \\
\text { manageable }\end{array}$ & Severe & $\begin{array}{l}\text { Constant and } \\
\text { disabling }\end{array}$ \\
\hline Resistance to the obsession & $\begin{array}{l}\text { Always } \\
\text { resist }\end{array}$ & $\begin{array}{l}\text { Often } \\
\text { resists }\end{array}$ & $\begin{array}{l}\text { Sometimes } \\
\text { can resist }\end{array}$ & $\begin{array}{l}\text { Only try to } \\
\text { resist }\end{array}$ & Cannot resist \\
\hline Control over the obsession & $\begin{array}{l}\text { Complete } \\
\text { control }\end{array}$ & $\begin{array}{l}\text { Much } \\
\text { control }\end{array}$ & Little control & $\begin{array}{l}\text { Some } \\
\text { control }\end{array}$ & No control \\
\hline Mild: 0-5, Moderate: 6-9, Severe: 10-14, Extreme: 15-20 & \multicolumn{5}{l|}{} \\
\hline
\end{tabular}

Table 2. Yale-Brown Obsessive Scale — Modified

\section{Sheehan Disability Scale}

The Sheehan Disability Scale evaluates one's quality of life and functional impairment at school/work, social and family life (Table 3)..$^{14,15}$ 
BDD

from page 133

\begin{tabular}{|l|c|c|c|c|c|c|c|c|c|c|c|}
\hline \multicolumn{10}{|c|}{ Sheehan Disability Scale } \\
\hline Criteria & $\begin{array}{c}\text { No } \\
\text { disturbance }\end{array}$ & $\begin{array}{c}\text { Mild-continue } \\
\text { routine but } \\
\text { concerned }\end{array}$ & $\begin{array}{c}\text { Moderate-worry } \\
\text { makes routine } \\
\text { incomplete }\end{array}$ & $\begin{array}{c}\text { Severe-wory } \\
\text { stops or reduces } \\
\text { routine activity }\end{array}$ & $\begin{array}{c}\text { Extreme-cannot } \\
\text { carry on routine } \\
\text { life }\end{array}$ \\
\hline Score & 0 & 1 & 2 & 3 & 4 & 5 & 6 & 7 & 8 & 9 & 10 \\
\hline $\begin{array}{l}\text { Work or } \\
\text { school }\end{array}$ & & & & & & & & & & & \\
\hline Social life & & & & & & & & & & & \\
\hline Family/home & & & & & & & & & & \\
\hline Mild: 0-9, Moderate: $10-18$, Severe: $19-27$, Extreme: $27-30$ \\
\hline
\end{tabular}

Table 3. Sheehan Disability Scale

\section{The Derriford Appearance Scale}

The Derriford Scale has 59 items or questions designed to assess the effect or concern of one's appearance on everyday living, personal relations, self-esteem, and emotional distress (Table 4). ${ }^{16}$ The scale has a subscale for general self-consciousness, social self-consciousness, sexual and bodily appearance, facial appearance, and negative self-concepts. A shortened version of the scale is often utilized. We used a 20-point scale modified for hair loss assessment although there are 24-point and 12-point scales already available. ${ }^{17,18}$ These modified questions also were not vetted for accuracy in identifying possible BDD clinically.

\begin{tabular}{|c|c|c|c|c|c|}
\hline & \multicolumn{5}{|c|}{ Derriford Appearance Short Scale - Modified } \\
\hline & \multicolumn{5}{|c|}{$\begin{array}{l}0 \text { Did not apply to me at all } \\
1 \text { Applied to me to some degree, or some of the time } \\
2 \text { Applied to me to a considerable degree, or a good part of time } \\
3 \text { Applied to me very much, or most of the time }\end{array}$} \\
\hline & Criteria & \multicolumn{4}{|c|}{ Score } \\
\hline & & $\begin{array}{c}0 \\
\text { Never }\end{array}$ & $\begin{array}{c}1 \\
\text { Sometimes } \\
\end{array}$ & $\begin{array}{c}2 \\
\text { Considerable }\end{array}$ & $\begin{array}{c}3 \\
\text { Always }\end{array}$ \\
\hline 1 & Feeling loss of Confidence & & & & \\
\hline 2 & Distress at Reflection & & & & \\
\hline 3 & Irritable at Home & & & & \\
\hline 4 & Feel Hurt, Feel Rejected & & & & \\
\hline 5 & Self Conscious of appearance & & & & \\
\hline 6 & Distress at Pubs Restaurants or Social events & & & & \\
\hline 7 & Misjudged due to appearance & & & & \\
\hline 8 & Feel incomplete masculine or feminine & & & & \\
\hline 9 & Felt I wasn't worth much as a person & & & & \\
\hline 10 & Adjust the hair if it flies or gets disturbed & & & & \\
\hline 11 & Adopt Concealing Gestures & & & & \\
\hline 12 & Difficult to work up the initiative to do things & & & & \\
\hline 13 & $\begin{array}{l}\text { Tended to over-react getting upset by quite trivial } \\
\text { situations }\end{array}$ & & & & \\
\hline 14 & $\begin{array}{l}\text { Found others preferred over me for important } \\
\text { assignments }\end{array}$ & & & & \\
\hline 15 & Felt sad and depressed sometimes & & & & \\
\hline 16 & $\begin{array}{l}\text { Found myself getting impatient when I was delayed in } \\
\text { any way } \\
\text { (eg, lifts, traffic lights, being kept waiting) }\end{array}$ & & & & \\
\hline 17 & Could have done better with proper looks & & & & \\
\hline 18 & Felt that I had nothing to look forward to & & & & \\
\hline 19 & Found it difficult to relax & & & & \\
\hline 20 & $\begin{array}{l}\text { Felt nervous in situations, with raised heart rate } \\
\text { sweating or shaking feet }\end{array}$ & & & & \\
\hline & :0-10, Moderate: $10-30$, Severe: $31-50$, Extreme: $51-60$ & & & & \\
\hline
\end{tabular}

Table 4. Derriford Appearance Short Scale — Modified

\section{Evaluation}

References from previous studies were used to decide a score to be labeled as BDD. ${ }^{14-18}$ Those who scored a 10 or higher on the Yale-Brown Scale or had a DASS score of 30 or higher showing preoccupation of the mind were considered to have BDD. Patients with a minimal defect requesting complete correction can perhaps clinically be considered to have BDD. A Sheehan Disability Score of greater than 30 indicated that the perception of the deformity affected the patient's daily life.

\section{Prevalence of BDD}

Younger patients in the age group of 18-30 had a higher perception of the magnitude of their deformity. The grade of hair loss and extent of thinning or baldness did not show direct correlation with the prevalence of BDD. On the Yale-Brown
Scale, $32 \%$ scored as mild, while a moderate score was seen in $40 \%$ of patients. A severe Yale-Brown Scale score of 10 and higher, perhaps indicating BDD, was seen in $27 \%$ of patients who had varying degrees of hair loss and grade III-VI of baldness. Only one patient who refused to attend college scored as extreme. Therefore, the prevalence of discomfort that may reflect BDD in hair loss patients as per the modified Yale-Brown Scale is $27 \%$. Again, it should be noted that the scale was modified to relate more directly to hair loss and that, accordingly, the correlation of the degree of discomfort to the question and the diagnosis of BDD lacks the richness of the unmodified scale and is, at best, speculative. Nevertheless, the incidence is higher when compared to patients in cosmetic surgery in general. The highest incidence of BDD reported in a study done for patients requesting rhinoplasty is $20.7 \% .^{13}$

Our modified Sheehan Scale showed that none of the patients had a mild score, $78 \%$ had moderate influence on their routine life, $20 \%$ scored as severe, and $2 \%$ scored as having an extreme effect on their routine life. This may indicate that, although the incidence of BDD in hair loss patients is low, the effect on daily life is more than generally perceived when scored by our modified Sheehan Scale,

The criteria of DASS were also selected and modified to fit hair loss patients. The modification may be one of the reasons that $82 \%$ of patients had a score of 31-50 indicating severe preoccupation with their hair loss. The remaining $18 \%$ had extreme effect, while no one reported mild or moderate effect. The study indicates that the loss of hair and change in appearance may have a higher and deeper impact on the minds and social lifestyle of our patients than we think. On the other hand, our modification of the questions in all of the scales may have created this effect.

We reassessed the patients 8 months after the hair restoration procedure. The Yale-Brown scores improved showing $48 \%$ mild, $36 \%$ moderate, $16 \%$ severe, and no extreme scores (Figure 1). The Sheehan Scale showed 32\% mild, $56 \%$ moderate, $12 \%$ severe, and no extreme scores (Figure 2). There was a 12-32\% shift toward a mild perception, $11-22 \%$ shift toward a moderate perception, $8-11 \%$ improvement in severe perceptions, and no one regarded the deformity as extreme. The shift indicates that hair restoration surgery does help to a large extent in improving the appearance, lifestyle, and perception of the deformity in hair loss patients.

The DASS modified scores reassessed after hair transplant revealed a slightly different outlook. Though the scores of $12 \%$ mild, 27\% moderate, and $45 \%$ severe indicated benefit from the procedure, nevertheless, $16 \%$ still scored as extreme (Figure 3) compared to the original $18 \%$ who scored as extreme before the surgical correction. Thus, patients who were in the extreme category before surgery were still preoccupied with their hair afterwards with thoughts including they had had a hair transplant, that others may notice the transplanted hair, that the residual thinning may still be seen, that areas of less hair could be visible to others, and that they would always have less hair than others around them. These are the patients to look out for. These patients may continue to be unhappy after the procedure and notice faults or incomplete execution of the procedure by holding on to residual deformities or perceptions of the deformities. Comparing a $27 \%$ incidence of BDD and $16 \%$ still considering that they had a deformity, should we conclude that only $11 \%$ of the BDD could be 


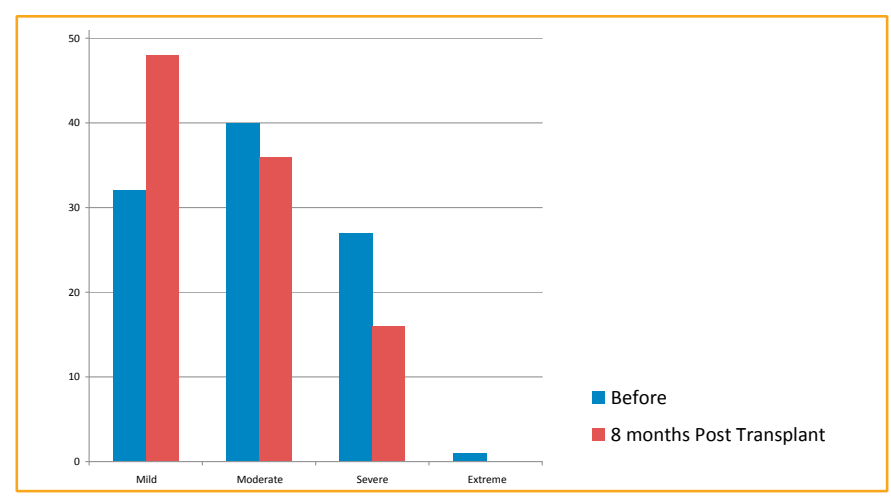

Figure 1. Yale-Brown Scale Improvement Before and After Hair Restoration

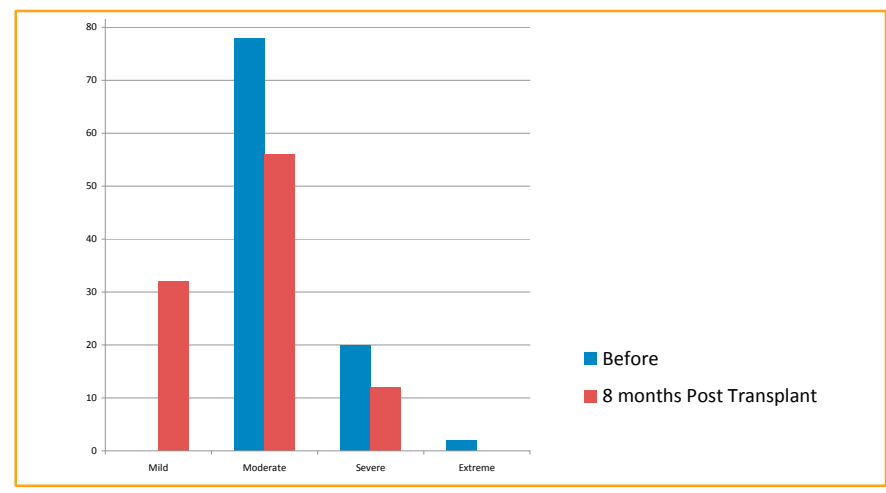

Figure 2. Sheehan Scale Improvement Before and After Hair Restoration

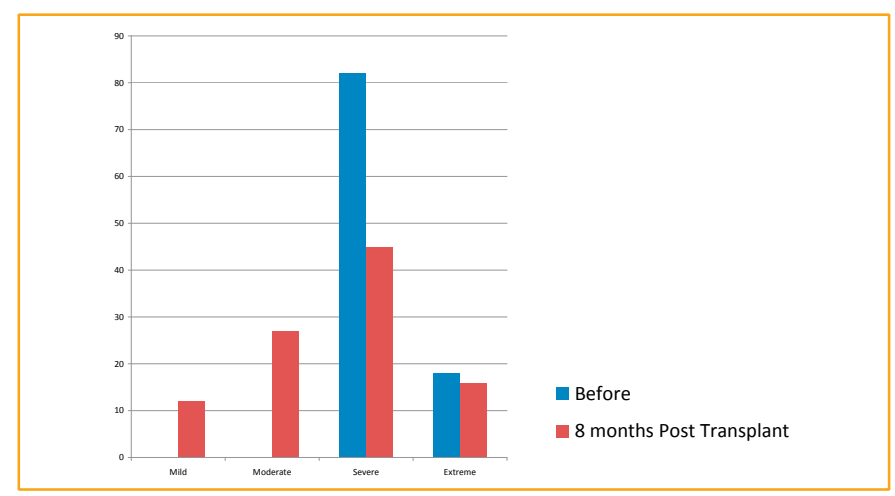

Figure 3. DASS Scale Shift towards Milder Perception of Disability after Hair Restoration

corrected or helped by surgery? The design of this study, including the modification of the scales, precludes deriving an answer to this interesting question.

At follow-up, patients who improved on their scores often noted that they felt more confident, could concentrate better at work, were socially more active, and had stopped using caps and concealers. Some, however, still had their favorite angle for photographs. Some began fitness regimens, some had undertaken qualifying exams or had received promotions. The families, who were asked to give their perception of the patient following the procedure, often found an emotionally improved and better bonding person. Younger patients and patients with lower grades of hair loss and with higher initial evaluation scores of the deformity, however, perceived less improvement and, accordingly, noted less satisfaction when they were reassessed at follow-up. Because patient satisfaction and quality of life are prime concerns in hair restoration, further research in correlation to BDD is necessary.

\section{References}

1. Sarwer, D.B., et al. The psychology of cosmetic surgery: a review and reconceptualization. Clin Psychol Rev. 1998; 18:1-22.

2. Sarwer, D.B., et al. Body image dissatisfaction and body dysmorphic disorder in 100 cosmetic surgery patients. Plast Reconstr Surg. 1998; 101:1644-1649.

3. Phillips, K.A. The Broken Mirror: Understanding and Treating Body Dysmorphic Disorder. New York: Oxford University Press; 1996.

4. Crerand, C.E., M.E. Franklin, and D.B. Sarwer. Body dysmorphic disorder and cosmetic surgery. Plast Reconstr Surg. 2006; 118:167e-180e.

5. Otto, M.W., et al. Prevalence of body dysmorphic disorder in a community sample of women. Am J Psychiatry. 2001; 158:2061-2063.

6. Faravelli, C., et al. Epidemiology of somatoform disorders: a community survey in Florence. Soc Psychiatry Psychiatr Epidemiol. 1997; 32:24-29.

7. Bohne, A., et al. Prevalence of body dysmorphic disorder in a German college student sample. Psychiatry Res. 2002; 109:101-104.

8. Cansever, A., et al. The prevalence and clinical features of body dysmorphic disorder in college students: a study in a Turkish sample. Compr Psychiatry. 2003; 44:60-64.

9. Sarwer, D.B., et al. Female college students and cosmetic surgery: an investigation of experiences, attitudes, and body image. Plast Reconstr Surg. 2005; 115:931-938.

10. Grossbart, T.A., and D.B. Sarwer. Psychosocial issues and their relevance to the cosmetic surgery patient. Semin Cutan Med Surg. 2003; 22:136-147.

11. Edgerton, M.T., M.W. Langman, and T. Pruzinsky. Plastic surgery and psychotherapy in the treatment of 100 psychologically disturbed patients. Plast Reconstr Surg. 1991; 88:594-608.

12. Veale, D., et al. Body dysmorphic disorder: a survey of fifty cases. Br J Psychiatry. 1996; 169:196-201.

13. Veale, D., L. De Haro, and C. Lambrou. Cosmetic rhinoplasty in body dysmorphic disorder. Br J Plast Surg. 2003; 56:546-551.

14. Cororve, M.B., and D.H. Gleaves. Body dysmorphic disorder: a review of conceptualizations, assessment, and treatment strategies. Clin Psychol Rev. 2001; 21:949-970.

15. Phillips, K.A., et al. A severity rating scale for body dysmorphic disorder: development, reliability, and validity of a modified version of the Yale-Brown Obsessive Compulsive Scale. Psychopharmacol Bull. 1997; 33:17-22.

16. Harris, D., T. Carr, and T. Moss. Manual for the Derriford Appearance Scale 59 (DAS59). Bradford on Avon: Musketeer Press; 1996.

17. Ching, S., et al. Measuring outcomes in aesthetic surgery: a comprehensive review of the literature. Plast Reconstr Surg. 2003; 111:469-480; discussion 481-482.

18. Harris, D.L., and A.T. Carr. The Derriford Appearance Scale (DAS59): a new psychometric scale for the evaluation of patients with disfigurements and aesthetic problems of appearance. Br J Plast Surg. 2001; 54:216-222. 